\title{
Nonpulmonary Organ Failure in ARDS: What Can We Modify?
}

Mortality in ARDS is often driven by multiple-organ system failure. ${ }^{1,2}$ This deterioration is thought to be secondary to extrapulmonary organ involvement due to a complex interplay between inflammatory mediators and ongoing injury due to ventilator mechanics. A common pro-inflammatory pathway due to an initial insult (eg, sepsis, aspiration pneumonitis, trauma) likely exists between multiple-organ system failure and ARDS. ${ }^{3}$ Ventilatorassociated lung injury has also been postulated as a precipitant for nonpulmonary organ failure, a concept referred to as biotrauma. ${ }^{4,5}$ What is less clear is how the timing of ARDS and nonpulmonary organ failure relate. Does nonpulmonary organ failure happen first or subsequently or simultaneously with ARDS? How does nonpulmonary organ failure relate to the severity of ARDS as defined by the Berlin criteria, a completely pulmonary-focused classification system? ${ }^{6}$ Finally, if the cause of death is not related to hypoxemia itself, is there another way that we should risk stratify patients with ARDS rather than with $\mathrm{P}_{\mathrm{aO}_{2}} / \mathrm{F}_{\mathrm{IO}_{2}}$ ?

In this issue of Respiratory CARE, Kallet et $\mathrm{al}^{7}$ presented observational data from 1,747 subjects over a $15-\mathrm{y}$ period from a quality assurance data base. The investigators collected data on ARDS severity and etiology as well as nonpulmonary organ dysfunction from the day of ARDS onset. Delivered tidal volumes were similar across the groups, with an incremental increase in plateau pressure and driving pressure as ARDS severity increased. More than $80 \%$ of the subjects had at least one nonpulmonary organ failure at onset, with increasing prevalence as ARDS severity increased, and the rate of nonpulmonary organ failure in severe ARDS was significantly higher than in mild or moderate disease. ${ }^{7}$ The number of failed organs and mortality rate increased with the severity of ARDS; acute renal and hepatic dysfunction as well as acidemia independently predicted mortality. ${ }^{7}$ Of the reported pulmonary variables, only severe ARDS was predictive of mortality in multivariable analysis. Importantly, the Berlin

\footnotetext{
The authors have disclosed no conflicts of interest.
}

Correspondence: Abhijit Duggal MD MPH MSc, Department of Critical Care Medicine, Respiratory Institute, Cleveland Clinic Foundation, 9500 Euclid Avenue, Cleveland, Ohio 44106. E-mail: duggala2@ccf.org.

DOI: $10.4187 /$ respcare 07008 severity classification ${ }^{6}$ correlated well with illness severity, the number of organs in failure, and mortality.

\section{See the Original Study on Page 493}

The investigators noted similar findings to the original Berlin definition study in terms of expected mortality rate by ARDS severity. ${ }^{6}$ When compared with the LUNG SAFE cohort, ${ }^{8}$ there are some key differences. Although the overall worst nonpulmonary SOFA ${ }^{9}$ score also increased with ARDS severity in LUNG SAFE, there was not a significant difference among the groups that used ARDS day-1 values only. This contrast suggests that organ dysfunction may worsen after ARDS day 1. Because the current study only evaluated patient characteristics on day 1 of ARDS, it is uncertain whether the differences in nonpulmonary organ dysfunction changed over time. If so, this raises the possibility that ventilator-associated lung injury plays a role in worsening organ function. There may also be value in reclassifying ARDS severity on day 2 after a standardized approach to ventilation because many patients' condition may change in severity, ${ }^{10}$ although it is unclear how this correlates with multiple-organ system failure. The progression of nonpulmonary organ failure over the course of mechanical ventilation for ARDS is an area for future study.

If patients present with nonpulmonary organ failure at a similar severity to ARDS severity, then the key question for clinicians and researchers is, how can that modify the disease course? What ventilator and nonventilator strategies could affect progression of organ failure? A secondary analysis of LUNG SAFE examined potentially modifiable factors as related to mortality ${ }^{11}$. Lower PEEP, high peak inspiratory pressure, plateau pressure, driving pressure, and breathing frequency were associated with a higher risk of death. Given the retrospective nature of this study, it was not possible to gauge the impact on nonpulmonary organ failure directly. ${ }^{11}$ Landmark studies in ARDS, whether relative to low tidal volume ventilation ${ }^{12}$ or adjunctive therapies ${ }^{13}$ reported a lower incidence of organ failure compared with controls but not any effects on existing organ dysfunction. At this point, it is difficult to know what parameters to follow up to monitor for improvement. Would changing ARDS severity day to day reflect a change in the overall disease course, including 


\section{EDITORIALS}

organ dysfunction? As demonstrated by Madotto et al, ${ }^{14}$ "resolved" ARDS on day 2 of illness compared with day 1 confers minimum clinical or mortality benefit, which likely reflects the complex nature of the underlying disease.

Given that severity of nonpulmonary organ failure correlates well with ARDS severity by the Berlin criteria, ${ }^{6}$ this presents opportunities for focused research, particularly of those with severe disease. Although much attention is paid to the description and manipulation of pulmonary mechanics, many of these factors (including PEEP, compliance, minute ventilation) were evaluated by the Berlin definition, ${ }^{6}$ which correlated poorly with the outcome. It is conceivable that the patients who are sickest have common nonpulmonary factors, by etiology or phenotype, ${ }^{15}$ that would lend themselves to targeted therapies. In addition, the progression of nonpulmonary organ failure could be assessed prospectively by examining characteristics related to how existing therapies are applied to these patients. Future investigations should focus on modifying existing organ failure in ARDS, which may ultimately affect mortality and other patient-centered outcomes.

\section{Matthew Siuba Abhijit Duggal Department of Critical Care Respiratory Institute Cleveland Clinic Foundation Cleveland, Ohio}

\section{REFERENCES}

1. Montgomery AB, Stager MA, Carrico CJ, Hudson LD. Causes of mortality in patients with the adult respiratory distress syndrome. Am Rev Respir Dis 1985;132(3):485-489.

2. Stapleton RD, Wang BM, Hudson LD, Rubenfeld GD, Caldwell ES, Steinberg KP. Causes and timing of death in patients with ARDS. Chest 2005;128(2):525-532.

3. Han S, Mallampalli RK. The acute respiratory distress syndrome: from mechanism to translation. J Immunol 2015;194(3):855-860.

4. Slutsky AS, Tremblay LN. Multiple system organ failure. Is mechanical ventilation a contributing factor? Am J Respir Crit Care Med 1998;157(6 Pt 1):1721-1725.
5. Tremblay LN, Slutsky AS. Ventilator-induced injury: from barotrauma to biotrauma. Proc Assoc Am Physicians 1998;110(6):482488.

6. ARDS Definition Task Force; Ranieri VM, Rubenfeld GD, Thompson BT, Ferguson ND, Caldwell E, et al. Acute respiratory distress syndrome: the Berlin Definition. JAMA 2012;307(23):2526-2533.

7. Kallet R, Lipnick M, Zhuo H, Pangilinan L, Gomez A. Characteristics of non-pulmonary organ dysfunction at the onset of ARDS based on the Berlin definition. Respir Care 2019;64(5):493-501.

8. Bellani G, Laffey JG, Pham T, Fan E, Brochard L, Esteban A, et al. LUNG SAFE Investigators; ESICM Trials Group. Epidemiology, patterns of care, and mortality for patients with acute respiratory distress syndrome in intensive care units in 50 countries. JAMA 2016;315(8):788-800.

9. Vincent JL, Moreno R, Takala J, Willatts S, De Mendoça A, Bruining $\mathrm{H}$, et al. The SOFA (Sepsis-related Organ Failure Assessment) score to describe organ dysfunction/failure. On behalf of the Working Group on Sepsis-Related Problems of the European Society of Intensive Care Medicine. Intensive Care Med 1996;22(7):707-710.

10. Villar J, Blanco J, del Campo R, Andaluz-Ojeda D, Diaz-Dominiquez FJ, Muriel A, et al. Spanish Initiative for Epidemiology, Stratification \& Therapies for ARDS (SIESTA) Network. Assessment of $\mathrm{PaO} 2 / \mathrm{FiO} 2$ for stratification of patients with moderate and severe acute respiratory distress syndrome. BMJ Open 2015; 5(3): 006812.

11. Laffey JG, Bellani G, Pham T, Fan E, Madotto F, Bajwa EK, et al LUNG SAFE Investigators and the ESICM Trials Group. Potentially modifiable factors contributing to outcome from acute respiratory distress syndrome: the LUNG SAFE study. Intensive Care Med 2016; 42(12): 1865-1876.

12. Acute Respiratory Distress Syndrome Network, Brower RG, Matthay MA, Morris A, Schoenfeld D, Thompson BT, Wheeler A. Ventilation with lower tidal volumes as compared with traditional tidal volumes for acute lung injury and the acute respiratory distress syndrome. N Engl J Med 2000;342(18):1301-1308.

13. Papazian L, Forel JM, Gacouin A, Penot-Ragon C, Perrin G, Loundou A, et al. ACURASYS Study Investigators. Neuromuscular blockers in early acute respiratory distress syndrome. N Engl J Med 2010; 363(12):1107-1116.

14. Madotto F, Pham T, Bellani G, Bos LD, Simonis FD, Fan E, et al. LUNG SAFE Investigators and the ESICM Trials Group. Resolved versus confirmed ARDS after $24 \mathrm{~h}$ : insights from the LUNG SAFE study. Intensive Care Med 2018;44(5):564-577.

15. Calfee CS, Delucchi K, Parsons PE, Thompson BT, Ware LB, Matthay MA, NHLBI ARDS Network. Subphenotypes in acute respiratory distress syndrome: latent class analysis of data from two randomised controlled trials. Lancet Respir Med 2014;2(8):611-620. 